Cite this: Phys. Chem. Chem. Phys., 2014, 16, 9128

Received 5th February 2014, Accepted 28th March 2014

DOI: 10.1039/c4cp00530a

www.rsc.org/pccp

\title{
Arresting consecutive steps of a photochromic reaction: studies of $\beta$-thioxoketones combining laser photolysis with NMR detection $\dagger$
}

\author{
Mariusz Pietrzak, *a Jacek Dobkowski, ${ }^{a}$ Alexandr Gorski, ${ }^{a}$ Sylwester Gawinkowski, ${ }^{a}$ \\ Michał Kijak, ${ }^{a}$ Roman Luboradzki, ${ }^{a}$ Poul Erik Hansen ${ }^{b}$ and Jacek Waluk*a
}

\begin{abstract}
Photochromism of monothiodibenzoylmethane has been studied in a number of environments at different temperatures. Direct laser irradiation of a sample located in the NMR magnet allowed in situ monitoring of the phototransformation products, determining their structure, and measuring the kinetics of the back reaction. These observations, along with the data obtained using electronic and vibrational spectroscopies for rare gas matrix-isolated samples, glasses, polymers, and solutions, as well as the results of quantum-chemical calculations, provide insight into the stepwise mechanism of the photochromism in $\beta$-thioxoketones. At low temperature in rigid matrices the electronic excitation leads to the formation of the $-\mathrm{SH}$ exorotamer of the $(Z)$-enethiol tautomer. In solutions, further steps are possible, producing a mixture of two other non-chelated enethiol forms. Photoconversion efficiency strongly depends on the excitation wavelength. Analysis of the mechanisms of the photochromic processes indicates a state-specific precursor: chelated thione-enol form in the excited $\mathrm{S}_{2}\left(\pi \pi^{\star}\right)$ electronic state. The results show the potential of using laser photolysis coupled with NMR detection for the identification of phototransformation products.
\end{abstract}

\section{Introduction}

Huge interest in photochromism is stimulated by numerous possible applications of this phenomenon. ${ }^{1-4}$ Photochromic transformations quite often involve proton transfer and/or conformational changes. A suitable, widely investigated system for studying the interplay between tautomeric and rotameric interconversion processes is provided by $\beta$-thioxoketones. ${ }^{5-28}$ In principle, these compounds can assume many different forms, as depicted in Fig. 1, which makes a reliable structural assignment of the forms involved in photochromism a very challenging task. After some controversies, ${ }^{6,9,12,13}$ it has now been established that $\beta$-thioxoketones exist in solution primarily as the thione-enol form (e-CCC) in equilibrium with the t-CCC form of Scheme 1, although the equilibrium constant does depend on the flanking groups (aliphatic or aromatic), temperature,

\footnotetext{
${ }^{a}$ Institute of Physical Chemistry, Polish Academy of Sciences, Kasprzaka 44/52, 01-224 Warsaw, Poland. E-mail: mpietrzak@ichf.edu.pl, jwaluk@ichf.edu.pl; Fax: +48 223433333; Tel: +48223433332

${ }^{b}$ Department of Science, Systems and Models, Roskilde University, DK-4000 Roskilde, Denmark. E-mail: poulerik@ruc.dk; Fax: +45 46742011; Tel: +4546742432

$\dagger$ Electronic supplementary information (ESI) available: Calculated structures and NMR parameters. CCDC 974809. For ESI and crystallographic data in CIF or other electronic format see DOI: 10.1039/c4cp00530a
}

and solvent. ${ }^{18,23}$ Irradiating at $410 \mathrm{~nm}$, the wavelength corresponding to the $S_{2}\left(\pi \pi^{*}\right)$ transition of the e-CCC form of monothiodibenzoylmethane (1), carried out for rare gas, glass, polymers, and $\mathrm{KBr}$ matrices, leads to proton transfer and trapping of the non-hydrogen bonded t-TCC species, a form that can be kept almost indefinitely below $90 \mathrm{~K}^{24}$ Increasing the temperature from 90 to $115 \mathrm{~K}$ results in over a thousand-fold decrease in the lifetime of the photochromic product. For instance, for $\mathbf{1}$ dissolved in 3-methylpentane, the lifetime drops from 1260 to $1 \mathrm{~min}^{27}$ It can be expected that, in a less rigid environment, other photochromic channels can be activated, e.g., those involving the rotation about the $\mathrm{C}-\mathrm{C}$ bond. No such structures have been reported so far. Therefore, the main goal of this work was to check for the presence of the currently unknown photochromic channels and to determine the structure of possible photochromic products.

In the above-mentioned cases the species were identified by means of IR and UV measurements. ${ }^{24-28}$ Here, we present another, novel approach, based on laser irradiation in the magnet combined with in situ NMR detection. This methodology provides an interesting possibility for studies of photoinduced reactions, although a number of technical difficulties have to be overcome. So far, the technique has been used to demonstrate the occurrence of syn-anti photoisomerization in the electron donor-acceptor molecule, 2-( $N$-methyl- $N$-isopropylamino)-5-cyanopyridine. ${ }^{29}$ Other applications included studies of photosensitized oxidation of 


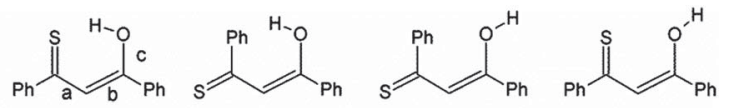

e-CCC e-TCC e-TCT e-CCT

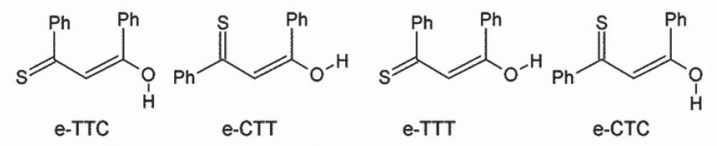

$\underbrace{\mathrm{T}-\mathrm{CCC}}_{\mathrm{t}-\mathrm{TCC}}$<smiles>O=C(/C=C(\SS)C(=O)c1ccccc1)/C=C(\SS/C(=C/C(=O)c1ccccc1)c1ccccc1)c1ccccc1</smiles>
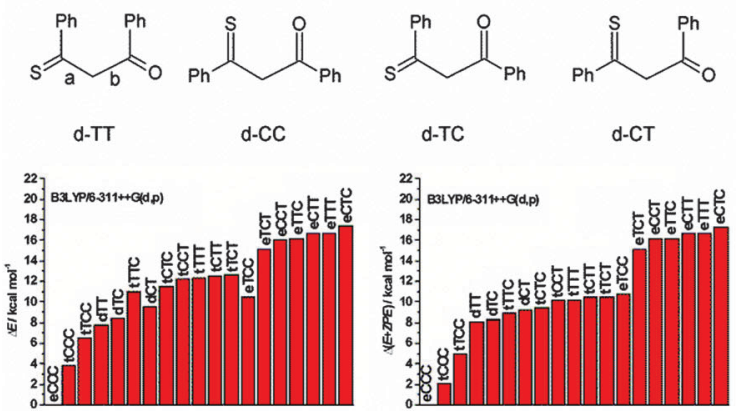

Fig. 1 Top, possible structures of monothiodibenzoylmethane. Bottom, calculated relative ground state energies without (left) and with (right) zero-point-energy correction.

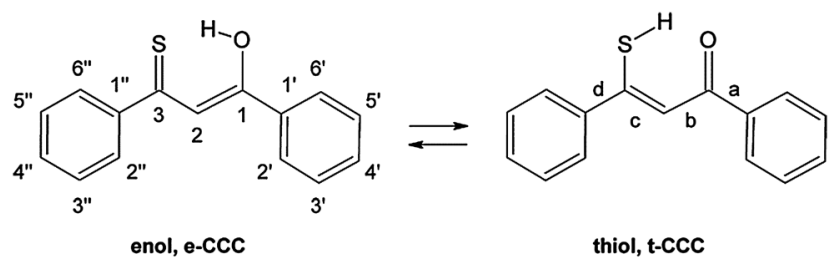

Scheme 1 Two main tautomeric forms of $\mathbf{1}$. The relevant dihedral angles are labeled $\mathrm{a}-\mathrm{d}$.

imidazole and guanosine derivatives, ${ }^{30-32}$ conformational changes in proteins, ${ }^{33,34}$ and RNA refolding. ${ }^{35,36}$ In the present investigation, monothiodibenzoylmethane $\mathbf{1}$ (Scheme 1) is investigated, as this compound is stable and many derivatives exist. The results obtained by combination of laser photolysis, NMR, electronic absorption, IR and Raman techniques, supported by density functional theory (DFT) and time-dependent DFT (TDDFT) calculations, provide information on geometric and vibrational structure, relative and electronic transition energies, as well as on NMR chemical shifts. We find that photochromic transformation of $\mathbf{1}$ involves several steps. In contrast to the situation encountered in a rigid environment, where the photoconversion leads to the t-TCC form, irradiation of solutions produces a mixture of t-CTC and t-TTC. These forms revert back to the most stable e-CCC and t-CCC structures on the time scale of days at $183 \mathrm{~K}$ and minutes at $293 \mathrm{~K}$.

\section{Experimental and computational details}

\section{Synthesis and preparation of samples}

1 was synthesized as described in ref. 19. The concentration of the NMR sample was usually 2 millimolar. The NMR solvents used, i.e. $\mathrm{CD}_{2} \mathrm{Cl}_{2}, \mathrm{CDCl}_{3}, \mathrm{CD}_{3} \mathrm{CN}, \mathrm{CD}_{3} \mathrm{OD}$, THF- $\mathrm{d}_{8}$, toluene- $\mathrm{d}_{8}$, acetone- $\mathrm{d}_{6}$, were obtained from Cambridge Isotopes Laboratories, Inc. or from Armar Chemicals. Each sample was prepared from fresh solvent from an ampoule without further purification. Solutions were bubbled with dry nitrogen for at least $10 \mathrm{~min}$ inside NMR tubes directly before measurements.

\section{NMR-laser setup}

The setup with the laser is depicted in Fig. 4. The laser beam is transmitted via three aluminium mirrors and focused with a quartz lens on the end of the quartz rod (length $1 \mathrm{~m}$ and diameter $3.8 \mathrm{~mm}$ ) inserted into the NMR magnet. The other end of the quartz rod is immersed in solution in a NMR tube hanging on the rod (for details see ESI $\dagger$ ). It is placed $1.5 \mathrm{~mm}$ above the upper end of the ${ }^{1} \mathrm{H}$ receiving coil as a compromise between the best irradiation of a measured volume and good magnetic field homogeneity.

\section{NMR experiments}

NMR measurements were performed on a Bruker AVANCE II 300 spectrometer operating at $300.1 \mathrm{MHz}$ for ${ }^{1} \mathrm{H}$ and $125.0 \mathrm{MHz}$ for ${ }^{13} \mathrm{C}$. For practical reasons (the solvents were thoroughly deoxygenated) TMS was not added and the ${ }^{1} \mathrm{H}$ and ${ }^{13} \mathrm{C}$ solvent signals were used as a chemical shift reference over the whole temperature range. This, of course, could lead to a small variation in the chemical shifts $\left(<0.1 \mathrm{ppm}\right.$ for $\left.{ }^{1} \mathrm{H}\right)$. In the case of mixed solvents (Fig. 8) the chemical shift was referenced directly to the internal TMS signal.

The temperature experiments were controlled by the BVT-3200 unit. Temperature was set with use of the methanol thermometer as a probe before each experiment. The temperature during irradiation was increased by at most $2{ }^{\circ} \mathrm{C}$.

Irradiation time was controlled using a NMR spectrometer by means of a shutter. After a period of laser irradiation a ${ }^{1} \mathrm{H}$ spectrum was recorded (16 scans, $2 \mathrm{~min}$ ) and the procedure was repeated until a steady-state was achieved. The reverse reaction was monitored by measuring ${ }^{1} \mathrm{H}$ spectra every $10-30$ minutes. The product was examined using the following NMR techniques: ${ }^{1} \mathrm{H}-{ }^{1} \mathrm{H}$ NOESY - (noesygpph, mixing time $1 \mathrm{~s}$ ), ${ }^{1} \mathrm{H}-{ }^{1} \mathrm{H}$ DQF COSY (cosygpmfph), ${ }^{1} \mathrm{H}-{ }^{13} \mathrm{C}$ correlations, i.e. HSQC - (hsqcopph, optimized for $170 \mathrm{~Hz}$ ), HMBC - (hmbcgplpndqf, zero and double quantum coherence, optimized for $8 \mathrm{~Hz}$ with low-pass J-filter for $170 \mathrm{~Hz}$ ).

\section{UV-Vis experiments}

The UV/Vis spectra were recorded on a Shimadzu UV2700 spectrophotometer, equipped with a home-made temperature 
control system. To monitor changes in the electronic spectra upon irradiation, the sample was cooled down to $205 \mathrm{~K}$ using a mixture of solid carbon dioxide and ethanol. DHOM-M-4451000 and DHOM-M-532-300 diode lasers with $1 \mathrm{~W}$ and $300 \mathrm{~mW}$ of maximum output power, respectively, were used as irradiation sources.

\section{IR/Raman experiments}

The IR spectra were recorded for room temperature dichloromethane solutions with $1 \mathrm{~cm}^{-1}$ resolution on a Nicolet Magna 560 FTIR spectrometer, equipped with an MCT/B liquidnitrogen-cooled detector. While recording the spectra of the photochromic products, the IR cell, placed in the sample chamber of the spectrometer, was irradiated using the DHOM-M-4451000 laser.

For the measurements of Raman spectra, a Renishaw InVia microscopic system was used, with two excitation sources: an HPNIR785 diode laser emitting at $785 \mathrm{~nm}$ and Stellar Pro Modu-Laser (LLC) emitting the $\mathrm{Ar}^{+} 514.5 \mathrm{~nm}$ line. The laser light was focused on a sample with a $30 \mathrm{~mm}$ focusing distance objective. The laser power at the sample was about $100 \mathrm{~mW}$. The Raman-scattered light was collected by the same objective through a cutoff filter to eliminate Rayleigh scattering. Gratings of 1800 and 1200 grooves $\mathrm{mm}^{-1}$ were used for 514.5 and $785 \mathrm{~nm}$ laser lines, respectively. The resolution was $5 \mathrm{~cm}^{-1}$ and the wavenumber accuracy was $2 \mathrm{~cm}^{-1}$, both calibrated with the Rayleigh line and the $520.6 \mathrm{~cm}^{-1}$ line of silicon. The Raman spectra were recorded using a $1024 \times 256$ pixel Peltier-cooled RenCam CCD detector. A Linkam THMS600 climatic chamber coupled to the system translation stage was used for measurements at low temperatures, down to $183 \mathrm{~K}$.

\section{X-ray studies}

Single crystal X-ray diffraction measurements were carried out on an Agilent Supernova diffractometer, at $100 \mathrm{~K}$ with graphite monochromated $\mathrm{Cu} \mathrm{Ka}$ radiation $(1.54184 \AA$ A). The data reduction was made by using CrysAlisPRO ${ }^{37}$ software. The structures were solved by direct methods and refined on $F^{2}$ by full-matrix least-squares by using SHELXS97 and SHELXL97. ${ }^{38}$ All non-hydrogen atoms were refined as anisotropic while hydrogen atoms were placed in calculated positions, and refined in riding mode. 1: MONOCLINIC, $P 21 / c, a=12.4853(3), b=7.2462(2)$, $c=13.1368(3) \AA, V=1176.59(5) \AA^{3}, Z=4, D_{\text {calc }}=1.357 \mathrm{~g} \mathrm{~cm}^{-1}$, $\mu=2.254 \mathrm{~cm}^{-1}, R_{1}=0.0330$ for $2099\left[F_{\mathrm{o}}>4 \mathrm{~s}\left(F_{\mathrm{o}}\right)\right]$ and 0.0354 for all data, $\mathrm{w} R_{2}=0.0939, S=1.076$.

CCDC 974809 contains the supplementary crystallographic data for this paper. ESI. $\dagger$

\section{Calculations}

All the theoretical calculations were carried out using the Gaussian 09 code. $^{39}$ Molecular geometries were fully optimized using the B3LYP variant of the density functional theory (DFT) ${ }^{40,41}$ with the 6-311++(d,p) basis set. Time-dependent DFT (TD-DFT) method has been used for geometry optimization of the excited singlet states. For the triplet state geometry optimizations, both TD-DFT/B3LYP/ 6-311++(d,p) and DFT/UB3LYP/6-311++(d,p) methods were used, yielding similar structures and relative energies. The $\mathrm{T}_{1}$ structures presented in Fig. S6-S12 (ESI †) correspond to the UB3LYP calculations. The NMR nuclear shieldings were calculated with B3LYP/ $6-311++(\mathrm{d}, \mathrm{p})$ using the GIAO method. ${ }^{42,43}$ The electronic transition energies were calculated for both ground and excited singlet and triplet state optimized geometries using TD-DFT with the same functional and basis set (B3LYP/6-311++(d,p)).

\section{Results}

\section{Irradiation experiments}

Monitoring photochromism by electronic absorption spectroscopy. Fig. 2 shows the results of photoirradiation of 1 in dichloromethane solution at $205 \mathrm{~K}$ using a $445 \mathrm{~nm}$ laser line. The evolution of the absorption spectra demonstrates that complete photoconversion can be readily achieved in less than 10 minutes. The quantum yield of the photoprocess was estimated to be $1.5 \pm 0.6 \%$. This value is practically the same as the quantum yield of the photochromic transformation of $\mathbf{1}$ in 3-methylpentane glass at $90 \mathrm{~K}(1.3 \pm 0.6 \%)$.

Contrary to the behavior observed for $445 \mathrm{~nm}$ excitation, when using the 532 laser line, the photochromic process is extremely slow. Correcting for the amount of photons absorbed at 445 and $532 \mathrm{~nm}$, the yield of photoconversion was found to be at least 100 times lower when irradiating into the lower energy band. The lower and higher energy regions correspond to $S_{1}\left(n \pi^{*}\right)$ and $S_{2}\left(\pi \pi^{*}\right)$ transitions of the enol e-CCC form, respectively. The observed difference in photoconversion efficiencies raises an important question about the precursor state of the photochromic product: it can be either the enol tautomer in its $S_{2}\left(\pi \pi^{*}\right)$ electronic state or the t-CCC thiol form, for which, as discussed below, the electronic absorption is predicted to be blue-shifted with respect to the enol.

The electronic spectrum of the photoproduct after irradiation at $445 \mathrm{~nm}$ (Fig. 2), with the highest intensity peak at

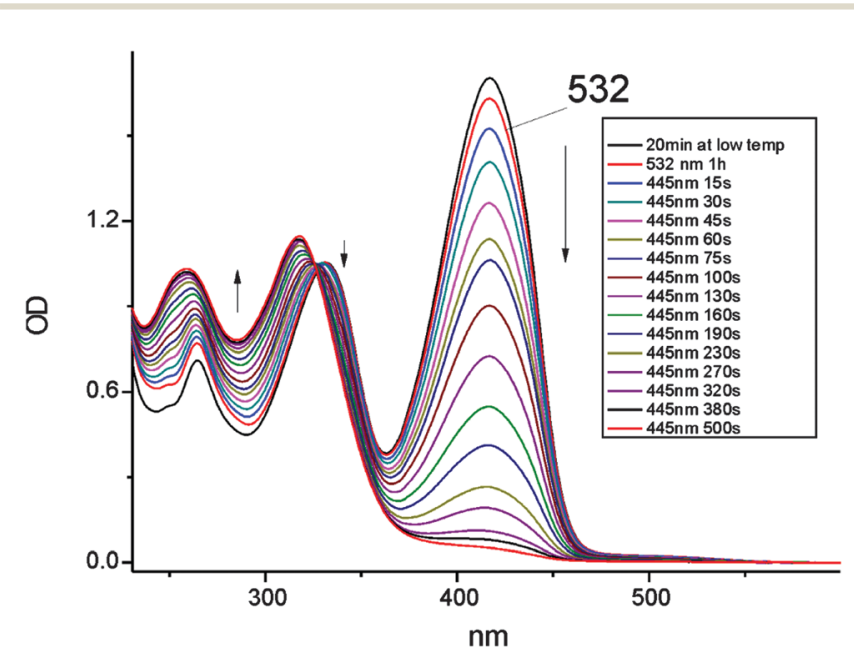

Fig. 2 Evolution of electronic absorption of 1 in dichloromethane at $205 \mathrm{~K}$. The sample was irradiated at $445 \mathrm{~nm}$ with a $50 \mathrm{~mW}$ laser line at intervals ranging between 15 and $120 \mathrm{~s}$. For comparison, the spectrum labeled " 532 " corresponds to 1 hour of irradiation at $532 \mathrm{~nm}$ with a laser power of $200 \mathrm{~mW}$. 
$318 \mathrm{~nm}$, resembles that obtained for the product of irradiation of 1 in high-viscosity media, such as rare gas matrices, polymers and glasses. However, the spectra are not identical, suggesting that the photochromic species produced under the two regimes are different. This is proven by the decay kinetics of the photoproduct. It disappears in less than a minute in a rigid environment at $120 \mathrm{~K}$, whereas in dichloromethane at $205 \mathrm{~K}$ the photochromic form persists for several hours; even at room temperature the photoproduct can be observed on the time scale of minutes. These results unequivocally show that the barrier for the depopulation of the photochromic species generated in solution is much higher than that required for the back reaction starting from the photoproduct obtained in the low temperature/rigid matrix regime.

IR/Raman measurements. $445 \mathrm{~nm}$ irradiation of a sample of 1 in dichloromethane at $183 \mathrm{~K}$ resulted in the disappearance of the Raman signal of the substrate. However, no signal from a photoproduct could be detected either. We interpret this as due to the fact that the electronic absorption of the most stable e-CCC form extends well to the red, thus fulfilling a preresonance condition for Raman excitation at $785 \mathrm{~nm}$. This is not the case for the photoproduct, of which the absorption is significantly blue-shifted. As described below, this hypothesis was confirmed by calculations.

On the other hand, the IR spectrum of the photoproduct could be registered even at room temperature. This spectrum was obtained while irradiating the solution of 1 in $\mathrm{CH}_{2} \mathrm{Cl}_{2}$ contained in the sample chamber of the FTIR spectrometer with $445 \mathrm{~nm}$ laser light. This led to the establishment of a photostationary regime, with about $20 \%$ depletion of the enol e-CCC form. The difference IR spectrum, presented in Fig. 3, was compared with the patterns theoretically predicted for various forms. Nice agreement between experiment and simulation is obtained for three thiol forms: t-TTC, t-CTC, and t-TCC.

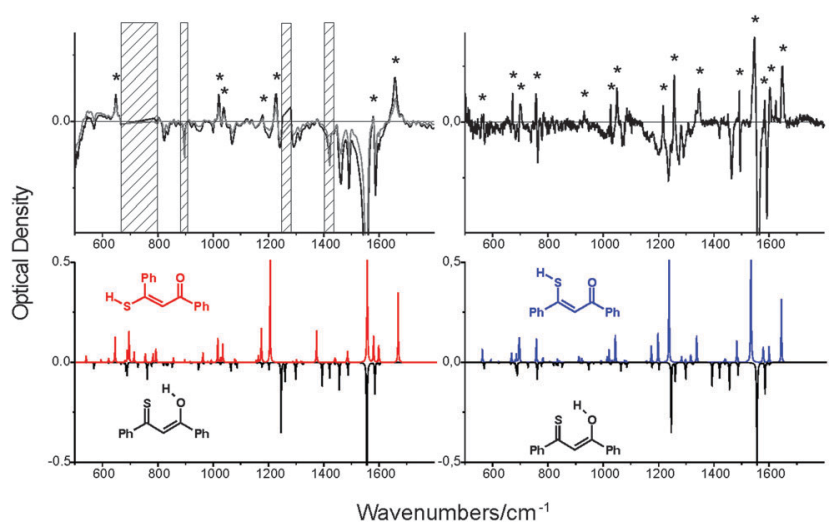

Fig. 3 Top left, a difference IR spectrum at $293 \mathrm{~K}$, obtained after subtracting the spectrum of non-irradiated $\mathrm{CH}_{2} \mathrm{Cl}_{2}$ solution from the spectrum recorded while irradiating the sample with a $455 \mathrm{~nm}$ laser line $(800 \mathrm{~mW})$. Top right, a difference spectrum obtained for an Ar matrix at $15 \mathrm{~K}$. The asterisks denote the bands corresponding to the photoproduct. For the Ar matrix, it has been identified as t-TCC. ${ }^{24}$ The hatched regions correspond to solvent absorption. Bottom, the IR spectra simulated for e-CCC (black, inverted), t-TTC (red, left) and t-TCC (blue, right). The spectrum simulated for t-CTC is practically identical to that of t-TTC.
We note, however, that the IR spectrum of the latter, obtained in rare gas matrices, is definitely different from the spectrum obtained for room temperature solution (Fig. 3). This suggests that the photoproduct generated at higher temperatures/lower viscosities may correspond to either t-TTC or t-CTC, or the mixture of both. Based on the IR spectra alone, this problem cannot be solved unambiguously.

Laser photolysis-NMR studies. The measurements were performed generally at $183 \mathrm{~K}$ in several different solvents: $\mathrm{CD}_{2} \mathrm{Cl}_{2}, \mathrm{CDCl}_{3}, \mathrm{CD}_{3} \mathrm{OD}, \mathrm{CD}_{3} \mathrm{CN}$, acetone- $\mathrm{d}_{6}$, and toluene- $\mathrm{d}_{8}$. The light source for most experiments was an argon laser, but some experiments were repeated with DPSS lasers emitting the light at 445 or $532 \mathrm{~nm}$. For a description of the light path see Fig. 4. The output was measured immediately before entering the light guide (see Fig. S1, ESI $\dagger$ for light guide and NMR tube arrangement). The dominant frequencies of the argon laser are the 514.5 and $488 \mathrm{~nm}$ lines together with a weaker line at $457.9 \mathrm{~nm}$. In most of the present experiments the weak $S_{1}\left(n \pi^{*}\right)$ transition of e-CCC is therefore primarily irradiated together with the $S_{2}\left(\pi \pi^{*}\right)$ transition. Experiments showed early on that oxygen in solution had a dramatic effect (Fig. S2, ESI $\dagger$ ). However, this type of photochemistry is not the subject of the present paper. Therefore, the solutions were freed of oxygen by thorough bubbling with dry nitrogen gas for at least $10 \mathrm{~min}$.

Using $\mathrm{CD}_{3} \mathrm{OD}, \mathrm{CD}_{3} \mathrm{CN}$ or acetone- $\mathrm{d}_{6}$ as solvent no product was observed. Using $\mathrm{CD}_{2} \mathrm{Cl}_{2}$ as solvent one well defined species (1id) was produced (see Fig. 5). Typical irradiation time for maximal conversion of the starting material using the argon laser ( $0.3 \mathrm{~W}$ at the sample) was $2-3$ hours in $\mathrm{CD}_{2} \mathrm{Cl}_{2}$. Using a laser at $445 \mathrm{~nm}(0.1 \mathrm{~W}$ at the sample) the time for full conversion was reduced to less than $20 \mathrm{~min}$. Using a laser at $532 \mathrm{~nm}$ no product could be observed. Discontinuing irradiation led to conversion to the original compound, $\mathbf{1}$, as seen from the spectrum in Fig. 5.

A very similar situation was found in $\mathrm{CDCl}_{3}$. In this case the formation of the product (1ic) upon irradiation was observed with similar speed to that for $\mathrm{CD}_{2} \mathrm{Cl}_{2}$. Also the reverse reaction in the darkness took place.

Irradiation of $\mathbf{1}$ in a thoroughly degassed toluene- $\mathrm{d}_{8}$ solution at $183 \mathrm{~K}$ for hours resulted in a product 1 it as seen in Fig. 6 . Discontinuation of the irradiation led to 1 : at $183 \mathrm{~K}$ only slowly (lifetime of a day), but quicker at higher temperatures (lifetime of an hour at $273 \mathrm{~K}$ and of minutes at $298 \mathrm{~K}$ ).

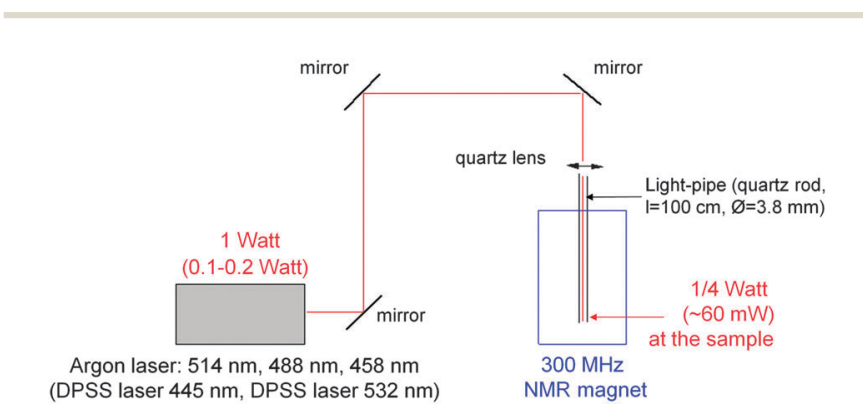

Fig. 4 Block diagram of the hyphenated NMR setup. For a full description see Experimental. 


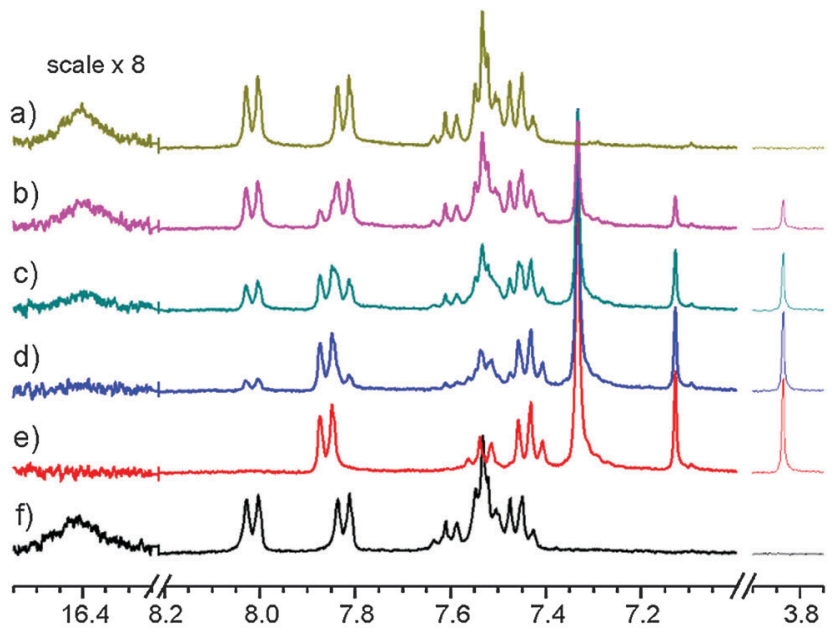

Fig. $5{ }^{1} \mathrm{H}$ NMR spectrum of 1 in $\mathrm{CD}_{2} \mathrm{Cl}_{2}$ at $208 \mathrm{~K}$. Irradiation at $445 \mathrm{~nm}$ (100 mW at the sample): (a) starting material; (b) irr. for $5 \mathrm{~min}$; (c) $10 \mathrm{~min}$; (d) $15 \mathrm{~min}$; (e) $20 \mathrm{~min}$; (f) after $30 \mathrm{~min}$ warm up to the room temp, recorded at $208 \mathrm{~K}$.

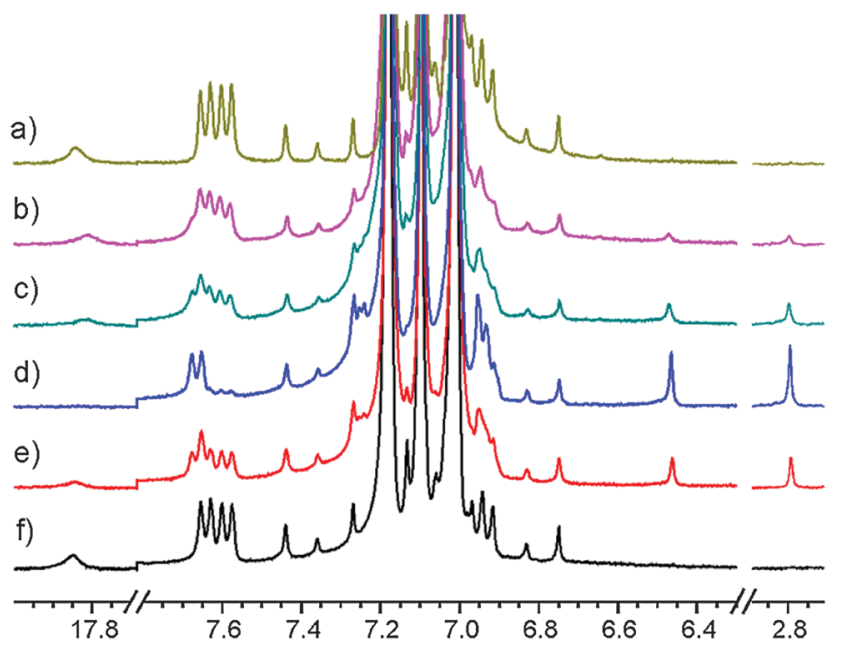

Fig. $6{ }^{1} \mathrm{H}$ NMR spectrum of 1 in toluene- $\mathrm{d}_{8}$ at $183 \mathrm{~K}$. Irradiation by an argon laser (ca. $0.3 \mathrm{~W}$ at the sample): (a) starting material; (b) irr. for $20 \mathrm{~min}$; (c) 1 hour; (d) 24 hours; (e) after 24 hours at $183 \mathrm{~K}$ in the dark; (f) after 10 min warm up to $273 \mathrm{~K}$, recorded at $183 \mathrm{~K}$.

Back reaction rates $1 / k$ [s] are as follows: $\mathrm{CD}_{2} \mathrm{Cl}_{2}$ at $183 \mathrm{~K}$ : $18000 ; \mathrm{CDCl}_{3}$ at $213 \mathrm{~K} 40000$ and toluene-d $\mathrm{d}_{8}$ at $183 \mathrm{~K}: 30000$. For $\mathrm{CD}_{2} \mathrm{Cl}_{2}$ at $183 \mathrm{~K}$ a much slower back reaction $(1 / k=200000)$ is found if the solvent is purified by passing through a column of basic aluminum oxide. For $\mathrm{CD}_{3} \mathrm{CN}$, methanol- $\mathrm{d}_{4}$ and acetone- $\mathrm{d}_{6}$ no products could be observed, so the back reaction rates could not be estimated.

\section{NMR assignments}

Based on the set of the following NMR spectra: ${ }^{1} \mathrm{H},{ }^{1} \mathrm{H}$ NOESY, ${ }^{1} \mathrm{H}-{ }^{1} \mathrm{H}$ correlation (COSY), ${ }^{1} \mathrm{H}-{ }^{13} \mathrm{C}$ correlations (HSQC, HMBC) we were able to assign most of the ${ }^{1} \mathrm{H}$ and ${ }^{13} \mathrm{C}$ signals. A complete analysis was done for the spectra recorded in $\mathrm{CD}_{2} \mathrm{Cl}_{2}$, a partial

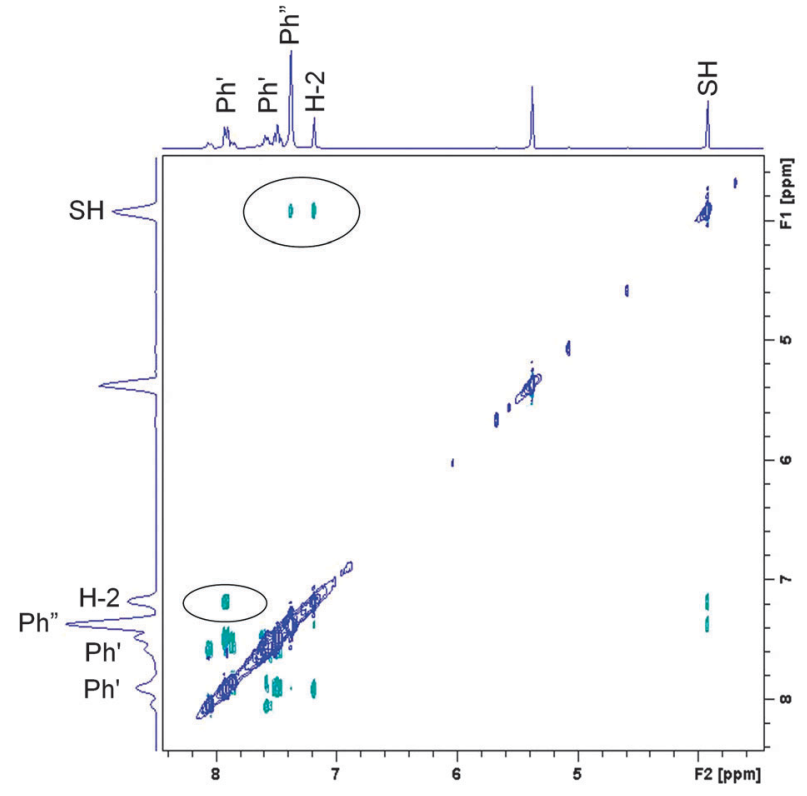

Fig. 7 NOESY spectrum of 1 id in $\mathrm{CD}_{2} \mathrm{Cl}_{2}$ at $183 \mathrm{~K}$.

one, for $\mathrm{CDCl}_{3}$ and toluene- $\mathrm{d}_{8}$. A proper starting point for the analysis of the NOESY spectrum (Fig. 7) is the singlet at $7.13 \mathrm{ppm}$ belonging to $\mathrm{H}-2$. A cross peak between this and the doublet at $7.86 \mathrm{ppm}$ assigns the latter as $\mathrm{H}-2^{\prime}$. This again is linked to the triplet at $7.43 \mathrm{ppm}$ being therefore $\mathrm{H}-3^{\prime} . \mathrm{H}-4^{\prime}$ is by default the less intense triplet at $7.52 \mathrm{ppm}$. All resonances belonging to hydrogens of the double prime ring are found in the pseudo singlet at $7.32 \mathrm{ppm}$ (confirmed in the HSQC spectrum). Cross peaks are also seen between the $\mathrm{SH}$ proton at $3.86 \mathrm{ppm}$ and those of $\mathrm{H}-2$ and the protons of the double prime ring.

The ${ }^{1} \mathrm{H}$ NMR spectrum of the compound formed in $\mathrm{CD}_{2} \mathrm{Cl}_{2}$ (1id) at $183 \mathrm{~K}$ can be summarized as (value in ppm, multiplicity, integral): $7.86\left(\mathrm{H}-2^{\prime}, \mathrm{d}, 2 \mathrm{H}\right), 7.52\left(\mathrm{H}^{-} 4^{\prime}, \mathrm{t}, 1 \mathrm{H}\right), 7.43\left(\mathrm{H}-3^{\prime}, \mathrm{t}, 2 \mathrm{H}\right)$, 7.32 (H-2" , H-3" , and H-4" , s, 5H), $7.13(\mathrm{H}-2, \mathrm{~s}, 1 \mathrm{H}), 3.86(\mathrm{SH}, \mathrm{s}$, $1 \mathrm{H})$. The ${ }^{1} \mathrm{H}$ NMR spectrum of the non-irradiated compound in $\mathrm{CD}_{2} \mathrm{Cl}_{2}$ (1d) at $183 \mathrm{~K}$ can be summarized as: $8.00\left(\mathrm{H}-2^{\prime}, \mathrm{d}, 2 \mathrm{H}\right)$, $7.80\left(\mathrm{H}-2^{\prime \prime}, \mathrm{d}, 2 \mathrm{H}\right), 7.60\left(\mathrm{H}-4^{\prime}, \mathrm{t}, 1 \mathrm{H}\right), 7.52(\mathrm{H}-2, \mathrm{~s}, 1 \mathrm{H}), 7.52\left(\mathrm{H}-4^{\prime \prime}\right.$, t, 1H), $7.51\left(\mathrm{H}-3^{\prime}, \mathrm{t}, 2 \mathrm{H}\right), 7.44\left(\mathrm{H}-3^{\prime \prime}, \mathrm{t}, 2 \mathrm{H}\right), 16.86(\mathrm{OH}, \mathrm{br}, 1 \mathrm{H})$. The ${ }^{1} \mathrm{H}$ NMR spectrum of the compound formed in $\mathrm{CDCl}_{3}(\mathbf{1 i c})$ at $213 \mathrm{~K}$ can be summarized as: $7.89\left(\mathrm{H}-2^{\prime}, \mathrm{d}, 2 \mathrm{H}\right), 7.51\left(\mathrm{H}-4^{\prime}, \mathrm{t}, 1 \mathrm{H}\right)$, $7.43\left(\mathrm{H}-3^{\prime}, \mathrm{t}, 2 \mathrm{H}\right), 7.36\left(\mathrm{H}-2^{\prime \prime}, \mathrm{H}-3^{\prime \prime}\right.$, and $\left.\mathrm{H}-4^{\prime \prime}, \mathrm{s}, 5 \mathrm{H}\right), 7.13(\mathrm{H}-2, \mathrm{~s}, 1 \mathrm{H})$, $3.8(\mathrm{SH}, \mathrm{s}, 1 \mathrm{H})$.

A NOESY spectrum of the 1it product (irradiation in toluene$\mathrm{d}_{8}$ ) is depicted in Fig. S3 (ESI $\dagger$ ). At $183 \mathrm{~K}$, it only shows a few cross peaks and these are of the positive phase due to the high viscosity of toluene at low temperature. Therefore we have repeated this experiment at $213 \mathrm{~K}$ to get negative cross peaks. Furthermore, the spectrum is dominated by very strong signals from toluene. A cross peak is seen from the doublet at $7.67 \mathrm{ppm}$ to a triplet at $6.92 \mathrm{ppm}$ and one from a doublet at $7.26 \mathrm{ppm}$ to a signal at $6.95 \mathrm{ppm}$. In addition, a cross peak is seen from the $\mathrm{SH}$ signal at $2.8 \mathrm{ppm}$ to the singlet at $6.5 \mathrm{ppm}$. The latter is the signal from the $\mathrm{H}-2$ proton. Based on these and supported by the theoretical calculations the following assignment can be 
made: $7.67\left(\mathrm{H}-2^{\prime}, \mathrm{d}\right), 7.26\left(\mathrm{H}-2^{\prime \prime}, \mathrm{d}\right), 6.92\left(\mathrm{H}-3^{\prime}, \mathrm{t}\right), 6.95\left(\mathrm{H}-3^{\prime \prime}\right)$, $6.5(\mathrm{H}-2, \mathrm{~s})$ and $2.8(\mathrm{SH}, \mathrm{s})$.

${ }^{13} \mathrm{C}$ NMR. Based on HSQC and HMBC spectra the ${ }^{13} \mathrm{C}$ spectrum of 1 id at $183 \mathrm{~K}$ can be assigned as follows [ppm]: C-1 187.2, C-2 118.9, C-3 154.0, C-1" 139.2, C-3" 127.9, C-2" and $\mathrm{C}-4^{\prime \prime}$ at 127.4 and 128.9 ; C-1' $137.3, \mathrm{C}-2^{\prime} 128.0, \mathrm{C}-3^{\prime} 128.3, \mathrm{C}-4^{\prime}$ 132.6. The compound measured under the same conditions before irradiation (in $\mathrm{CD}_{2} \mathrm{Cl}_{2}$ at $183 \mathrm{~K}$ 1d) exhibited the following signals: C-1 177.3, C-2 109.7, C-3 211.5, C-1" at 145.3, C-2" 126.6, C-3" 128.7, C-4" 131.4, C-1' 133.8, C-2' 126.8, C-3' 128.2, C-4' 133.8 .

\section{DFT calculations of the NMR parameters}

As described above, many different enol and thioenol structures can be constructed together with several diketo forms. Ground state structures, energies, and ${ }^{1} \mathrm{H}$ and ${ }^{13} \mathrm{C}$ chemical shifts have been calculated. The NMR parameters were not computed for the diketo forms, as the NMR spectra clearly show their absence. It is interesting to notice that all but two lowest thiol forms have very similar energies, especially when zero point energies are taken into account (Fig. 1). Moreover, except for the lowest energy e-CCC structure, all other enol forms have energies higher than the thiol species.

NMR data. The calculated ${ }^{1} \mathrm{H}$ nuclear shielding of the thiol forms for the $\mathrm{H}-2$ and $\mathrm{SH}$ protons are discussed in terms of the structures given in Scheme 2. The structures in Scheme 2 can be described in the following fashion: $\mathrm{A}$ : $\mathrm{H}-2$ is "trans" to $\mathrm{CO}$; $\mathrm{B}$ : $\mathrm{H}-2$ is "cis" to CO; C: $\mathrm{SH}$ is cis to $\mathrm{Ph}$ and $\mathrm{S}$ is close to O; D: $\mathrm{SH}$ is cis to $\mathrm{Ph}$ and $\mathrm{S}$ is not close to $\mathrm{O}$, and finally $\mathrm{E}$ : $\mathrm{SH}$ is trans to $\mathrm{Ph}$ and $\mathrm{S}$ is not close to $\mathrm{O}$. For $\mathrm{H}-2$ of A the following shieldings are found: $24.73,24.64,24.50$, and 24.62. For H-2 of B: 25.53, 25.03, 25.31 and 25.39. For the SH proton of C: 28.00 , for the $\mathrm{SH}$ proton of D: $28.48,28.49$, and 28.96, and for the SH proton of $\mathrm{E}$ : $27.34,27.88$, and 27.74. The averages of these can be translated into chemical shifts firstly by comparison with calculated shielding values for TMS and drawing the linear correlation<smiles>O=C(c1ccccc1)C(c1ccccc1)C(S)c1ccccc1</smiles>

A<smiles>O=C(/C=C(/S)c1ccccc1)c1ccccc1</smiles>

$C$<smiles>O=C(c1ccccc1)C(c1ccccc1)C(S)c1ccccc1</smiles>

B

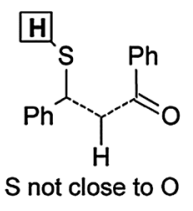

D

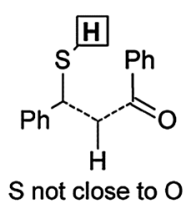

$\mathrm{E}$
Scheme 2 Possible tautomeric/rotameric structures (A-E), classified according to the calculated ${ }^{1} \mathrm{H}$ chemical shielding of $\mathrm{H}-2$ and $\mathrm{SH}$ (indicated by squares). Dashed line corresponds to both cis and trans forms. SH means orientation of no importance. Structures $A, B$ are analysed for $\delta(\mathrm{H}-2): \mathrm{A}=\mathrm{t}-\mathrm{CCC}, \mathrm{t}-\mathrm{TCC}, \mathrm{t}-\mathrm{TTC}, \mathrm{t}-\mathrm{CTC} ; \mathrm{B}=\mathrm{t}-\mathrm{CCT}, \mathrm{t}-\mathrm{TTT}, \mathrm{t}-\mathrm{CTT}, \mathrm{t}-\mathrm{TCT}$. Structures $C, D, E$ are analysed for $\delta(\mathrm{SH}): C=t-T C C ; D=t-T C T, t-T T C$, t-TTT; $=\mathrm{t}-\mathrm{CCT}$, t-CTT, t-CTC. with the experimental data to give A $7.20 \mathrm{ppm}$, B $6.45 \mathrm{ppm}$, C $3.77 \mathrm{ppm}$, D $3.11 \mathrm{ppm}$, and E $4.10 \mathrm{ppm}$.

Plots of the ${ }^{1} \mathrm{H}$ observed $v s$. calculated chemical shifts for 1d and 1id are given in Fig. S4 and S5 (ESI $\dagger$ ), respectively.

Structures. Of special interest is the conjugation in the compounds and the possible effects of ring currents. The dihedral angles marked a, b, c and d are shown in Scheme 1. Structures of t-CCC and t-TCC are found to be rather planar, whereas the remaining structures are nonplanar, culminating with t-CTT and t-TTT.

\section{Discussion}

\section{Structure of 1id}

It is obvious from the ${ }^{1} \mathrm{H}$ NMR data that 1id is not a diketo form, as no resonances are found in the 5-6 ppm range. In order to distinguish whether the enol or thiol tautomer is formed, we have to analyse the ${ }^{13} \mathrm{C}$ chemical shifts of $\mathrm{C}=\mathrm{X}$. The finding of the ${ }^{13} \mathrm{C}$ resonance of $\mathrm{C}=\mathrm{X}$ at $187.2 \mathrm{ppm}$ is a clear proof that this chemical shift corresponds to $\mathrm{C}=\mathrm{O}$. The signals of $\mathrm{C}=\mathrm{S}$ are typically shifted more downfield ${ }^{44}$ and the $1 \mathbf{d}$ form, dominated by e-CCC, exhibits a signal at $211.5 \mathrm{ppm}$, corresponding to $\mathrm{C}=\mathrm{S}$. The calculated chemical shifts are around $230-250 \mathrm{ppm}$ for $\mathrm{C}=\mathrm{S}$ (enol forms) and around 190-200 ppm for $\mathrm{C}=\mathrm{O}$ (thiol forms). Naturally, hydrogen bonding to the solvent can also take place influencing the chemical shifts to some extent. ${ }^{23}$

The finding that the SH form is dominant is also supported by the ${ }^{1} \mathrm{H}$ chemical shifts of the $\mathrm{XH}$ proton at $3.86 \mathrm{ppm}$, because such a value is characteristic rather for $\mathrm{SH}$, whereas $\mathrm{OH}$ signals are usually shifted more downfield, as shown from the NMR calculations (Table S1, ESI $\dagger$ ). The hydrogen-bonded thiol form t-CCC is likewise excluded. The t-TCC form found in the experiment irradiating at $415 \mathrm{~nm}$ at $90 \mathrm{~K}$ is likewise not found, in good agreement with the low barrier to return found for this intermediate. The structural assignment of $1 \mathrm{id}$ is based on a combination of chemical shifts and NOE data. The finding of a cross peak between the $\mathrm{SH}$ proton and $\mathrm{H}-2$ clearly shows that those two protons are on the same side of the double bond. The chemical shifts of the $\mathrm{H}-2$ proton $(7.13 \mathrm{ppm})$ assign this proton and the oxygen to be on opposite sides of the double bond (structure A in Scheme 2). These two criteria only leave two possible structures for 1id, t-CTC and t-TTC (see Fig. 1). The finding of a NOE cross peak between the SH proton and the protons of the double prime ring (Scheme 1) points towards the t-TTC form. On the other hand, the SH chemical shift (3.86 ppm) points towards E of Scheme 2, corresponding to t-CTC and, most probably, both species exist in equilibrium. The relevant proton-proton distances for all calculated enol and thiol tautomers are presented in Table S2 (ESI $\dagger$ ).

The product obtained in $\mathrm{CDCl}_{3}, \mathbf{1 i c}$, is identical to $\mathbf{1 i d}$, as judged from the ${ }^{1} \mathrm{H}$ NMR spectrum and from the value of the reverse reaction rate.

\section{Structure of 1 it}

As seen in the Results section, the ${ }^{1} \mathrm{H}$ chemical shifts of $\mathbf{1 i t}$ and 1id are rather different, which could suggest that both 


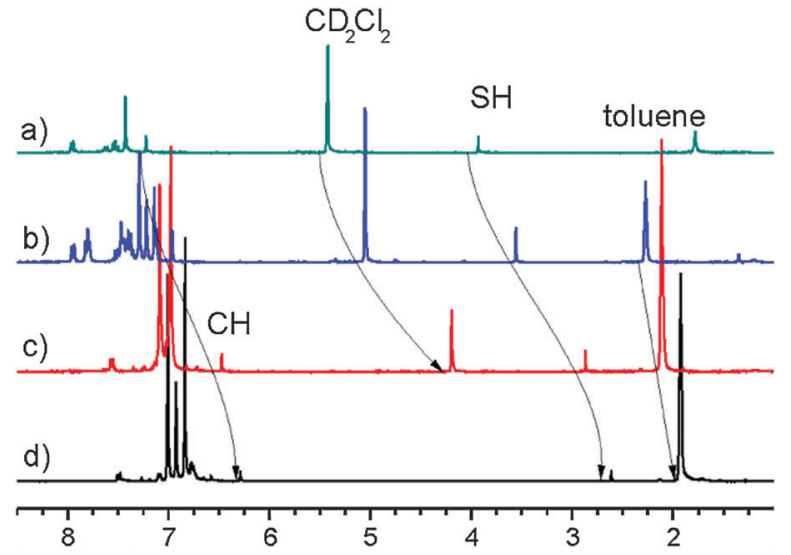

Fig. $8{ }^{1} \mathrm{H}$ NMR spectra of 1 after irradiation at $183 \mathrm{~K}$. Scale referenced to internal TMS; (a) $\mathrm{CD}_{2} \mathrm{Cl}_{2}$; (b) $\mathrm{CD}_{2} \mathrm{Cl}_{2}$ and toluene- $\mathrm{d}_{8}$ (5:1); (c) $\mathrm{CD}_{2} \mathrm{Cl}_{2}$ and toluene- $d_{8}(1: 1) ;(d)$ toluene- $d_{8}$.

structures are not the same. On the other hand, the solvent effect on the chemical shifts in toluene is specific. Ring currents of toluene lead to the low-frequency shifts of ${ }^{1} \mathrm{H}$ signals, which makes the comparison to the spectra in the other solvents complicated. However, the 2D-NOESY experiment exhibits cross-peaks between the same protons as in the case of 1id (see Fig. 7 and Fig. S3, ESI $\dagger$ ). The identical structures of 1id and 1it are also supported by the experiment in mixed solvents $\left(\mathrm{CD}_{2} \mathrm{Cl}_{2}\right.$ : toluene- $\mathrm{d}_{8} 5: 1$ and $\left.1: 1\right)$, as seen in Fig. 8. The changes in the $\mathrm{SH}$ and $\mathrm{CH}$ chemical shifts at growing concentration of toluene have a smooth character and are similar to the behaviour of solvent peaks. Moreover, the reverse reaction in the dark is as slow as for $\mathbf{1 i d}$. Therefore, we can conclude that 1it has the same structure as 1id.

\section{Conversion back to 1}

Is the conversion of $1 \mathrm{id}$ and 1it back to $\mathbf{1}$ feasible? In the context it should be considered that both 1id and 1it are so-called twisted push-pull ethylenes. The calculated twist (the $\mathrm{S}, \mathrm{C}=\mathrm{C}, \mathrm{C}$ dihedral angle) is $10^{\circ}$ and $8^{\circ}$ for t-TTC and t-CTC, respectively. Sandström and co-worker have found that barriers to rotation around the double bonds in such systems are not very high. ${ }^{45}$

\section{Modeling of the photoreaction path}

In order to understand the mechanisms of the multistep photochromic transformation in $\mathbf{1}$, we considered all five experimentally observed species as well as the relevant transition states. Ground state structure optimizations were followed by calculations of transition energies originating at $\mathrm{S}_{0}$ geometries. In the next step, geometries of the lowest excited singlet and triplet states were optimized. The calculated ground state geometry of the e-CCC form is in very good agreement with the X-ray structure (Fig. S6, ESI $\dagger$ ). The optimized $\mathrm{S}_{0}, \mathrm{~S}_{1}, \mathrm{~T}_{1}$, and transition state geometries of all five forms are presented in Fig. S7 (ESI $\dagger$ ). We have also repeated the calculations for thiomalonaldehyde (Fig. S8-S12, ESI $\dagger$ ), a model system, for which all five forms are predicted to be planar in the ground state.
The patterns of the relative energies obtained for both molecules turned out to be very similar, which indicates that the origin of the behavior of $\mathbf{1}$ is due to the electronic structure of the thiomalonaldehyde core, not to the symmetry-lowering perturbation of the substitution by phenyl rings. In this context, we also note that the X-ray study of 1-(1-methylcyclopropyl)-3thioxobutan-l-one, a $\beta$-thioxoketone with aliphatic substituents, ${ }^{46}$ revealed a very similar core geometry to that of $\mathbf{1}$ (the differences in bond lengths of about $0.01 \AA$, the angles between bonds agreeing within 1 degree).

The relative energies calculated for different tautomers/ rotamers of $\mathbf{1}$ are shown in Scheme 3. The first important finding concerns the relative energies of the two most stable forms, e-CCC and t-CCC. In agreement with experiment, their energies are predicted to be similar, with the chelated thiol form higher by $4 \mathrm{kcal} \mathrm{mol}^{-1}$ ( $2 \mathrm{kcal} \mathrm{mol}^{-1}$ after ZPE correction). In contrast, for the $S_{1}$ and $T_{1}$ excited states the calculations predict a large destabilization, of the order of $10 \mathrm{kcal} \mathrm{mol}^{-1}$ or more, of the thiol with respect to the enol tautomer. This prediction is crucial for the understanding of photochromism, as the first photoproduct, "open" thiol t-TCC is obviously generated from t-CCC. Since the excited state e-CCC $\rightarrow$ t-CCC reaction is predicted to be strongly uphill in $S_{1}$ and $T_{1}$, the effective way to produce t-TCC is either by direct excitation of t-CCC or via the $\mathrm{S}_{2}\left(\pi \pi^{*}\right)$ state of e-CCC. This conclusion is in excellent agreement with the observed huge dependence of the photoconversion efficiency on the excitation wavelength. It is well established for many thiocarbonyl compounds that the ability of sulfur to form hydrogen bonds decreases upon excitation to $S_{1}\left(n \pi^{*}\right)$, but increases in $S_{2}\left(\pi \pi^{*}\right) .{ }^{47-49}$ Moreover, the lifetime of $S_{2}\left(\pi \pi^{*}\right)$ can be as long as hundreds of picoseconds, ${ }^{50,51}$ but it can be effectively quenched by specific interactions with such solvents as acetonitrile ${ }^{52,53}$ or water. ${ }^{54}$ These findings not only provide a strong indication that the main precursor of the photochromism is the $S_{2}\left(\pi \pi^{*}\right)$ state of e-CCC: they also explain why there is no photoreaction in methanol or acetonitrile. Naturally, the reaction can also be initiated by direct excitation of t-CCC, but the ground state population is dominated by the enol, which also has a stronger absorption than the thiol at the wavelengths used. Therefore the contribution by direct excitation of this species should be minor, especially at lower temperatures. We finally recall that the open thiol can be generated photochemically at very low temperatures, when only the enol form is initially present in the ground state. $^{24}$

The calculations predict that the e-CCC to t-CCC conversion is strongly endoenergetic in both $S_{1}$ and $T_{1}$ (Scheme $3 \mathrm{~A}$ ). Attempts to optimize $S_{2}$ were not successful. For model molecules with hydrogen atoms or methyl groups instead of phenyls, $\mathrm{S}_{2}$ optimization assuming $C_{\mathrm{s}}$ symmetry of t-CCC ends up in e-CCC. These results indicate the e-CCC $\left(S_{2}\right) \rightarrow t-C C C\left(S_{1}\right)$ as the most probable path.

Once the excited t-CCC has been produced, it can be transformed into t-TCC. The $\mathrm{S}_{1}$ optimized $\mathrm{t}$-CCC and $\mathrm{t}$-TCC structures converge to identical geometries, with the $\mathrm{SH}$ bond almost perpendicular to the OC1C2C3S plane. This structure 

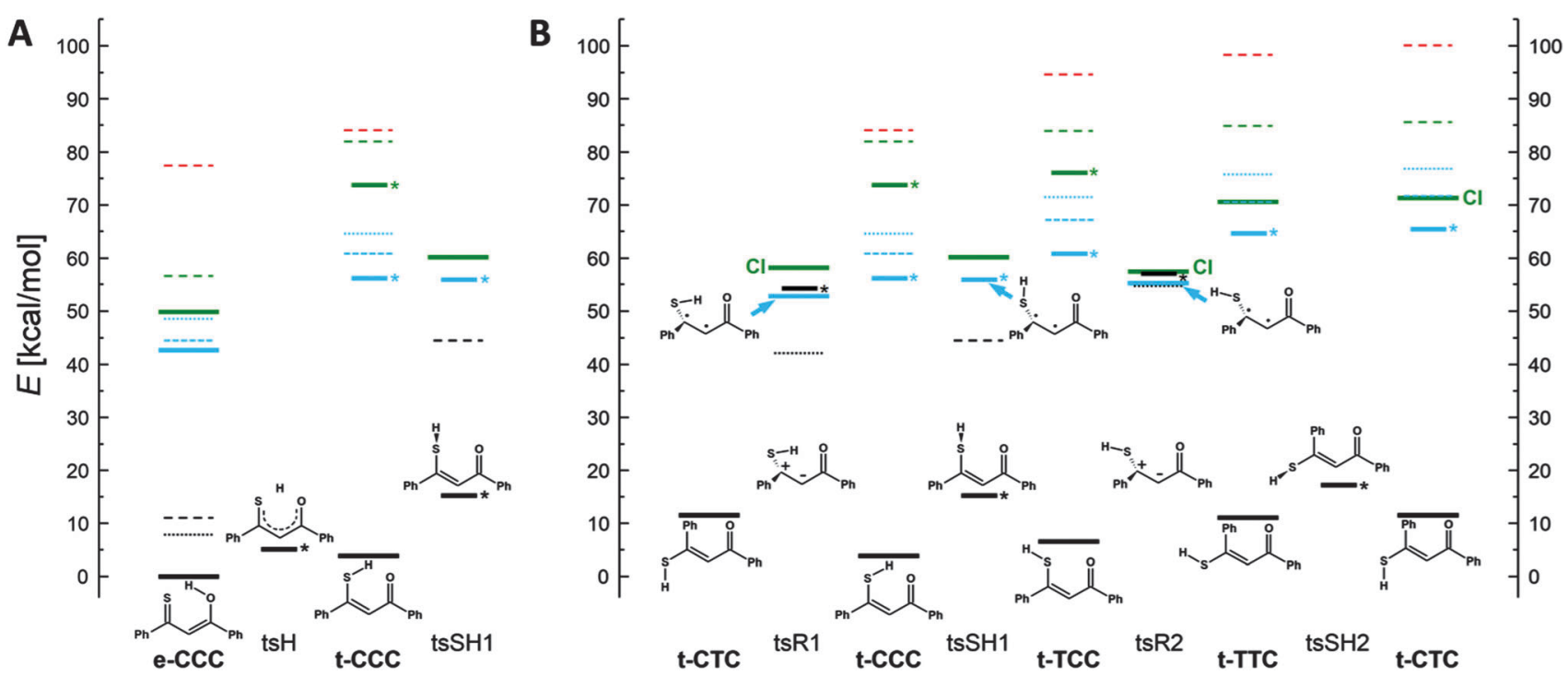

Scheme 3 Calculated relative ground (black) and $T_{1}$ (blue), $S_{1}$ (green) and $S_{2}$ (red) excited state energies of the experimentally observed forms of 1 and of the predicted transition states. Solid lines indicate optimized geometries. The vertical energies computed for the optimized geometries are indicated by dashed $\left(S_{1}\right.$ and $S_{2}$ at $S_{0}, S_{0}$ at $\left.S_{1}\right)$ or dotted $\left(T_{1}\right.$ at $S_{0}$ and $S_{0}$ at $T_{1}$ ) lines. The vertical $T_{1}$ energies were computed by both TD-DFT (short dashed lines) and UB3LYP (dots). Transition states are indicated by asterisks. Cl indicates non-fully optimized structure, due to the proximity of states.

(tsSH1 in Scheme 3A and B) corresponds in $\mathrm{S}_{0}$ to the transition state between $\mathrm{t}-\mathrm{CCC}$ and $\mathrm{t}-\mathrm{TCC}$. Thus, the $\mathrm{S}_{1}-\mathrm{S}_{0}$ relaxation (favourable because of a small energy gap) can lead to both forms.

In order to understand the next step of photochromism, the transformation into t-TTC and/or t-CTC, we note that the optimized $\mathrm{S}_{1} / \mathrm{T}_{1}$ (and probably also $\mathrm{S}_{2}$ ) states have in these structures higher energies than tsSH1. However, the structures in which the molecule is twisted about the $\mathrm{C} 2 \mathrm{C} 3$ bond (tsR1 and tsR2 in Scheme 3) have in $\mathrm{S}_{1}$ a lower energy than tsSH1. These structures correspond in the ground state to high energy (40-50 kcal mol${ }^{-1}$ ) transition states for rotation about a double bond. Full geometry optimization of the twisted forms was not possible, because of close-lying $\mathrm{S}_{0}$ and $\mathrm{S}_{1}$ states, characteristic of this type of structure and possibly leading to a conical intersection (CI). The $\mathrm{S}_{1}$ energies presented in Scheme 3 correspond therefore to upper limits. One can conclude that once the molecule overcomes the barrier from tsSH1 to tsR1 or tsR2, it can immediately convert (via conical intersection) into t-CTC and t-CCC (from tsR1) or into t-TTC and t-CTC (from tsR2). The $\mathrm{t}$-TTC and t-CTC are practically isoenergetic in $\mathrm{S}_{0}(0.5 \mathrm{kcal}$ $\mathrm{mol}^{-1}$ difference) and separated by a small barrier for the SH group rotation $\left(6 \mathrm{kcal} \mathrm{mol}^{-1}\right)$. Most probably the equilibrium is established between the two forms.

The behaviour predicted for the triplet states using UB3LYP is somewhat similar to that described above for $\mathrm{S}_{1}$. Except e-CCC, no structures with planar skeleton are obtained: they all relax to the twisted tsR1 and tsR2 forms (Scheme 3B). Contrary to the situation in $\mathrm{S}_{1}$, also the tsSH1 form is nonplanar; it now corresponds to the transition state between tsR1 and tsR2. Thus, the fate of excited molecules which underwent rapid proton transfer is similar to those in $S_{1}$. Now, however, the twisting leading to one of the tsR forms is barrierless. Even though no CI is predicted for these forms, the $T_{1}-S_{0}$ energy gap is very small.
On the basis of calculations we conclude that photochromism involving large amplitude motion is possible both in singlet and triplet manifolds. Because of expected large efficiency of intersystem crossing to the triplet and the barrierless character of tsSH1 $\rightarrow$ tsR forms, the triplet path seems to be more probable.

The crucial parameter for the t-TCC $\rightarrow$ t-TTC, t-CTC conversion is the $\mathrm{C} 2 \mathrm{C} 3$ bond length (Scheme 1), as, formally, the process involves a rotation about a double bond. The values calculated for ground and excited states are very instructive in this regard. For $S_{0}$, the calculations predict 136, 135, and $135 \mathrm{pm}$ for t-TCC, t-TTC, and t-CTC, respectively. For the relevant $\mathrm{S}_{1}$ structure, tsSH1, a value of $139 \mathrm{pm}$ is obtained, whereas the calculations for the triplet tsR1 and tsR2 forms yield $146 \mathrm{pm}$. These results clearly demonstrate the weakening of the double bond character in the triplet state. Together with the relative energies calculated for the three forms, they provide strong arguments that the large amplitude transformation leading to the photochromic products observed in solution occurs via the triplet state.

As was already mentioned above, the rotation about the double bond in the ground state involves a large energy barrier. In principle, an alternative mechanism is possible, with the participation of the diketo form. First, the SH hydrogen atom is transferred from t-CTC to C2 carbon with partial twisting, and then back to either sulphur or oxygen, with further twisting. However, the calculated barriers to these processes are only slightly lower (still above $40 \mathrm{kcal} \mathrm{mol}^{-1}$ ). The experimental finding that this reaction takes minutes at room temperature indicates that the real mechanism is different. The large change of the reaction rate in $\mathrm{CD}_{2} \mathrm{Cl}_{2}$ after removal of acid traces from the solvent supports the reaction pathway involving protonation of the $\mathrm{C}=\mathrm{O}$ group of $\mathrm{t}-\mathrm{CTC}$ and/or t-TTC. Initial calculations 
support this hypothesis, yielding for the protonated form a barrier of $20 \mathrm{kcal} \mathrm{mol}^{-1}$.

The barrier to rotation about the $\mathrm{C} 1 \mathrm{C} 2$ single bond is very small (ca. $2 \mathrm{kcal} \mathrm{mol}{ }^{-1}$ ). The t-TTT form is calculated to lie higher in energy than t-TTC. The experiment suggests that if it is formed, its concentration is below that required for NMR detection.

\section{Conclusions}

The use of "hyphenated techniques" such as laser irradiation combined with NMR detection at low temperature enables the observation and identification of new unstable species. By varying the temperature and viscosity, it was possible to observe the consecutive steps of photochromic transformation in monothiodibenzoylmethane. Irradiation of $\mathbf{1}$ in a rigid environment at temperatures of about $100 \mathrm{~K}$ or lower leads to the formation of t-TCC, a structure characterized by opening of the intramolecular hydrogen bond. Such a rotamer is stable below $100 \mathrm{~K}$, but returns to the main e-CCC form upon heating up. The situation in a nonrigid environment, i.e. liquid solution, is different. Now, the end products of the irradiation are t-CTC and t-TTC. The reaction path we propose includes photoinduced transformation from e-CCC in the $S_{2}\left(\pi \pi^{*}\right)$ state to t-CCC, followed by the hydrogen bond opening which leads to t-TCC. This step is possible even at very low temperatures and in rigid media, contrary to the second stage of the photochromic transformation, rotation about the C2C3 bond of the thiol t-TCC form. This reaction can only proceed in less viscous environments. The opening of the hydrogen bond may occur in both the excited singlet and the triplet state of t-CCC, but the next stage most probably goes only through $\mathrm{T}_{1}$. The dark reaction, i.e., the recovery of the most stable form of $\mathbf{1}$ is much longer than the photoinduced reaction. It is because the rotation along the double $\mathrm{C}=\mathrm{C}$ bond in the ground state has a relatively high barrier. The proposed scheme of the photochromism of $\mathbf{1}$ is shown in Scheme 4 .

An observation relevant for the understanding of the mechanism of photochromism is the extremely small yield for excitation into the low energy region where only e-CCC absorbs into

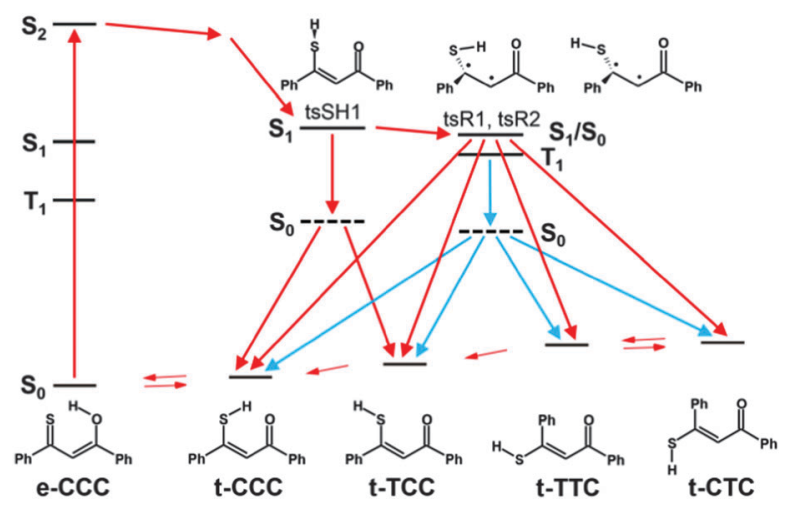

Scheme 4 The proposed photochromic pathways. Red and blue arrows denote singlet and triplet routes, respectively. Dashed lines indicate hot ground state molecules with geometry corresponding to the $S_{1}$ or the $T_{1}$ excited state. its $S_{1}\left(n \pi^{*}\right)$ state. Combined with the theoretical prediction of a large shift of the enol-thiol equilibrium towards the enol form, this finding strongly suggests lack of proton transfer from e-CCC to t-CCC in the $S_{1}$ and $T_{1}$ excited states. In consequence, the precursor of the photochromism is state-specific: e-CCC enol in $S_{2}\left(\pi \pi^{*}\right)$. Another argument for this postulate is the lack of photochromism in methanol and acetonitrile, as for these solvents the $\mathrm{S}_{2}$ lifetime can be drastically reduced. The directly excited t-CCC can only contribute at high temperatures, and even then the absorption will be dominated by e-CCC.

The structural assignments of t-CTC and t-TTC provided by NMR for $\mathrm{CD}_{2} \mathrm{Cl}_{2}$ and $\mathrm{CDCl}_{3}$ solutions seem to be very reliable. The product in toluene- $\mathrm{d}_{8}$ is most likely the same. Quantitative description of the kinetics of photochromism in $\beta$-thioxoketones requires time-resolved experiments spanning many orders of magnitude, from femtoseconds to minutes or even days. Such studies are now underway. We note the application potential of compounds for which the photochromic properties depend on solvent, temperature, viscosity, and excitation wavelength. Finally, one should stress that using the NMR detection for direct, in situ monitoring of unstable products of photochemical transformations opens up many new avenues in all areas requiring unequivocal structural assignments.

We hope that the complicated scheme of processes responsible for the photochromism in $\beta$-thioxoketones can provide a challenge for the rapidly growing area of theoretical description of photoinduced proton/hydrogen transfer phenomena. ${ }^{55-65}$

\section{Acknowledgements}

The authors wish to thank Professor Fritz Duus, Roskilde for advice. This work has been supported by the Polish Ministry of Science and Higher Education grant no. N N204 239 134, by the Polish National Science Centre grants no. DEC-2011/01/B/ST4/01130 and DEC-2011/ 03/B/ST4/02621, and the PL-Grid Infrastructure grant.

\section{Notes and references}

1 Photochromism. Molecules and Systems, ed. H. Dürr and H. Bouas-Laurent, Elsevier, 2003.

2 Molecular Switches, ed. B. L. Feringa and W. R. Browne, Wiley-VCH, Weinheim, Germany, 2nd edn, 2011.

3 M. Irie, Photochem. Photobiol. Sci., 2010, 9, 1535-1542.

4 W. Schnabel, Polymers and Light: Fundamentals and Technical Applications, Wiley-VCH, Weinheim, Germany, 2007.

5 J. Fabian, Tetrahedron, 1973, 29, 2449-2456.

6 O. Siiman, J. Fresco and H. B. Gray, J. Am. Chem. Soc., 1974, 96, 2347-2353.

7 W. F. Rowe, R. W. Duerst and E. B. Wilson, J. Am. Chem. Soc., 1976, 98, 4021-4023.

8 L. Carlsen and F. Duus, J. Am. Chem. Soc., 1978, 100, 281-282.

9 L. Carlsen and F. Duus, J. Chem. Soc., Perkin Trans. 2, 1979, 1532-1534.

10 L. Carlsen and F. Duus, J. Chem. Soc., Perkin Trans. 2, 1980, 1768-1773. 
11 F. S. Jørgensen, L. Carlsen and F. Duus, J. Am. Chem. Soc., 1981, 103, 1350-1353.

12 J. Gebicki and A. Krantz, J. Chem. Soc., Chem. Commun., 1981, 486-488.

13 J. Gebicki and A. Krantz, J. Am. Chem. Soc., 1981, 103, 4521-4526.

14 P. E. Hansen, F. Duus and P. Schmitt, Org. Magn. Reson., 1982, 18, 58-61.

15 F. S. Jørgensen, R. S. Brown, L. Carlsen and F. Duus, J. Am. Chem. Soc., 1982, 104, 5922-5926.

16 U. Berg, J. Sandström, L. Carlsen and F. Duus, J. Chem. Soc., Perkin Trans. 2, 1983, 1321-1325.

17 L. Nørskov-Lauritsen, L. Carlsen and F. Duus, J. Chem. Soc., Chem. Commun., 1983, 496-498.

18 F. Duus, J. Am. Chem. Soc., 1986, 108, 630-638.

19 P. E. Hansen, U. Skibsted and F. Duus, J. Phys. Org. Chem., 1991, 4, 225-232.

20 L. González, O. Mó and M. Yáñez, J. Phys. Chem. A, 1997, 101, 9710-9719.

21 L. González, O. Mó and M. Yáñez, J. Org. Chem., 1999, 64, 2314-2321.

22 N. Došlić, K. Sundermann, L. González, O. Mó, J. GiraudGirard and O. Kühn, Phys. Chem. Chem. Phys., 1999, 1, 1249-1257.

23 B. Andresen, F. Duus, S. Bolvig and P. E. Hansen, J. Mol. Struct., 2000, 552, 45-62.

24 Y. Posokhov, A. Gorski, J. Spanget-Larsen, F. Duus, P. E. Hansen and J. Waluk, Chem. Phys. Lett., 2001, 350, 502-508.

25 Y. Posokhov, A. Gorski, J. Spanget-Larsen, F. Duus, P. E. Hansen and J. Waluk, ChemPhysChem, 2004, 5, 495-502.

26 A. Gorski, Y. Posokhov, B. K. V. Hansen, J. Spanget-Larsen, J. Jasny, F. Duus, P. E. Hansen and J. Waluk, Chem. Phys., 2006, 328, 205-215.

27 A. Gorski, Y. Posokhov, B. K. V. Hansen, J. Spanget-Larsen, J. Jasny, F. Duus, P. E. Hansen and J. Waluk, Chem. Phys., 2007, 338, 11-22.

28 B. K. V. Hansen, A. Gorski, Y. Posokhov, F. Duus, P. E. Hansen, J. Waluk and J. Spanget-Larsen, Vib. Spectrosc., 2007, 43, 53-63.

29 J. Dobkowski, J. Wójcik, W. Koźmiński, R. Kołos, J. Waluk and J. Michl, J. Am. Chem. Soc., 2002, 124, 2406-2407.

30 C. Sheu, P. Kang, S. Khan and C. S. Foote, J. Am. Chem. Soc., 2002, 124, 3905-3913.

31 P. Kang and C. S. Foote, J. Am. Chem. Soc., 2002, 124, 4865-4873.

32 P. Kang and C. S. Foote, J. Am. Chem. Soc., 2002, 124, 9629-9638.

33 T. l. Kühn and H. Schwalbe, J. Am. Chem. Soc., 2000, 122, 6169-6174.

34 S. M. Harper, L. C. Neil, I. J. Day, P. J. Hore and K. H. Gardner, J. Am. Chem. Soc., 2004, 126, 3390-3391.

35 P. Wenter, B. Furtig, A. Hainard, H. Schwalbe and S. Pitsch, Angew. Chem., Int. Ed., 2005, 44, 2600-2603.

36 J. Buck, B. Furtig, J. Noeske, J. Wohnert and H. Schwalbe, Proc. Natl. Acad. Sci. U. S. A., 2007, 104, 15699-15704.

37 M. Lausmann, I. Zimmer, J. Lex, H. Lueken, K. Wieghardt and E. Vogel, Angew. Chem., Int. Ed. Engl., 1994, 33, 736-739.

38 G. M. Sheldrick, Acta Crystallogr., Sect. A: Fundam. Crystallogr., 2008, 64, 112-122.
39 M. Frisch, et al., Gaussian 09, Revision B.01, Gaussian, Inc., Wallingford, CT, 2010.

40 C. Lee, W. Yang and R. G. Parr, Phys. Rev. B: Condens. Matter Mater. Phys., 1988, 37, 785-789.

41 A. D. Becke, J. Chem. Phys., 1993, 98, 5648-5652.

42 R. Ditchfield, Mol. Phys., 1974, 27, 789-807.

43 K. Wolinski, J. F. Hinton and P. Pulay, J. Am. Chem. Soc., 1990, 112, 8251-8260.

44 A. R. Katritzky, S. Sobiak and C. M. Marson, Magn. Reson. Chem., 1988, 26, 665-670.

45 J. Sandström, U. Sjöstrand and I. Wennerbeck, J. Am. Chem. Soc., 1977, 99, 4526-4527.

46 L. Nørskov-Lauritsen, L. Carlsen and F. Duus, J. Chem. Soc., Chem. Commun., 1983, 496-498.

47 E. Krystkowiak, J. Koput and A. Maciejewski, Phys. Chem. Chem. Phys., 2012, 14, 8842-8851.

48 G. J. Zhao and K. L. Han, ChemPhysChem, 2008, 9, 1842-1846.

49 G. J. Zhao and K. L. Han, Acc. Chem. Res., 2012, 45, 404-413.

50 A. Maciejewski, D. R. Demmer, D. R. James, A. SafarzadehAmiri, R. E. Verrall and R. P. Steer, J. Am. Chem. Soc., 1985, 107, 2831-2837.

51 A. Maciejewski and R. P. Steer, Chem. Rev., 1993, 93, 67-98.

52 G. Burdzinski, A. Maciejewski, G. Buntinx, O. Poizat and C. Lefumeux, Chem. Phys. Lett., 2004, 384, 332-338.

53 M. Lorenc, A. Maciejewski, M. Ziolek, R. Naskrecki, J. Karolczak, J. Kubicki and B. Ciesielska, Chem. Phys. Lett., 2001, 346, 224-232.

54 G. Burdzinski, A. Maciejewski, G. Buntinx, O. Poizat, P. Toele, H. Zhang and M. Glasbeek, Chem. Phys. Lett., 2004, 393, 102-106.

55 Y. Syetov, J. Fluoresc., 2013, 23, 689-696.

56 M. Savarese, P. A. Netti, C. Adamo, N. Rega and I. Ciofini, J. Phys. Chem. B, 2013, 117, 16165-16173.

57 Y. Houari, A. Charaf-Eddin, A. D. Laurent, J. Massue, R. Ziessel, G. Ulrich and D. Jacquemin, Phys. Chem. Chem. Phys., 2014, 16, 1319-1321.

58 H.-H. G. Tsai, H.-L. S. Sun and C.-J. Tan, J. Phys. Chem. A, 2010, 114, 4065-4079.

59 Y. Shigemitsu, T. Mutai, H. Houjou and K. Araki, J. Phys. Chem. A, 2012, 116, 12041-12048.

60 M. Barbatti, A. J. A. Aquino, H. Lischka, C. Schriever, S. Lochbrunner and E. Riedle, Phys. Chem. Chem. Phys., 2009, 11, 1406-1415.

61 N. Kungwan, R. Daengngern, T. Piansawan, S. Hannongbua and M. Barbatti, Theor. Chem. Acc., 2013, 132, 1-10.

62 N. Kungwan, F. Plasser, A. J. A. Aquino, M. Barbatti, P. Wolschann and H. Lischka, Phys. Chem. Chem. Phys, 2012, 14, 9016-9025.

63 R. De Vivie-Riedle, V. De Waele, L. Kurtz and E. Riedle, J. Phys. Chem. A, 2003, 107, 10591-10599.

64 J. Jankowska, M. F. Rode, J. Sadlej and A. L. Sobolewski, ChemPhysChem, 2012, 13, 4287-4294.

65 A. L. Sobolewski and W. Domcke, Phys. Chem. Chem. Phys., 1999, 1, 3065-3072. 